\title{
Walking-Relations: On The Walk by Robert Walser and All This Can Happen by Siobhan Davies and David Hinton
}

Maren Butte, University of Bayreuth

\begin{abstract}
The article explores figurations of movement in Siobhan Davies' and David Hinton's found footage film All This Can Happen (2012), which refers to the work of prose The Walk (Der Spaziergang, 1917) by Robert Walser. It focuses on walking as act from a perspective of movement analysis in performance and dance studies. The essay unfolds questions about the filmic rhythm and montage in relation to the bodily movement of walking and its discursive contexts. It analyzes figurations like rhythm and pace, balance and imbalance, (dis-)orientation, relations to space and to others (choreography, social dimensions). This article argues that Davis's and Hinton's mise en scène generates a specific mode of physically engaged, aesthetic experience for the viewer by blending in visual composition with sensations of bodily movement.

Keywords: walking as act, movement analysis, flâneur, choreography, relationality, performance studies, dance studies, (post-)modernity, rhythm, montage, bewegungsgestalt
\end{abstract}

Choreographer Siobhan Davies' and writer David Hinton's fifty-minute film, All This Can Happen (2012) is a referential found footage film. ${ }^{1}$ It adapts of the work of prose The Walk (Der Spaziergang) by German writer Robert Walser from 1917 into a collage about a day-long walk around a small town. The Walk and All This Can Happen evolve from the bodily activity of walking. In Walser, it is unfolded in words, and Davies and Hinton create a rhythmic combination of imagery, sound, and text-arranged within the medium of film. In this article, I explore the acts of walking within both works by analyzing dimensions of movement. In examining walking as practice, both works can be read in choreographic terms as they set bodies and environment, time, and space into relation: they create walking-relations. ${ }^{2}$ Walking is not only topic or matter in The Walk and All This Can Happen, but form. In both pieces, choreographic dimensions of walking, like flow and irregularity, balance and imbalance, moments of potential falling, disorientation, and also social dimensions of walking as practice, have sedimented in rhythmic compositions. Particularly, the montage of All This Can Happen provides an aesthetic perception for the viewers that can be characterized as an 
affective participation and as an experience of liminality based on the use of transformed walking acts.

\section{Walking Acts}

Before analyzing the walking acts in The Walk and All This Can Happen, this article must pose some introductory remarks on walking as bodily practice. Walking can be characterized as a social, cultural, and performative practice that is learned by mimesis and is yet individual in its course of motion. In his essay, Der Gemessene Schritt (the measured step), Ulrich Giersch understands walking as "Bewegungsgestalt" (gestalt of movement), ${ }^{3}$ following Marcel Mauss' concept of body techniques and describes it as a process of alternating tension and release of muscles and body-parts which produces a fragile equilibrium and an ephemeral moment of levitation. ${ }^{4}$ Anticipating and reacting at the same time, the body is being balanced upwards from feet and legs while a complete set of muscles is being engaged in a multitude of micro-movements. A constant process of adjustment and compensation is being commenced which is based not only on the visual sense but on muscular senses as well (proprioception). ${ }^{5}$ Giersch argues that walking is not a neutral locomotion but an affective bodily activity including thinking processes. ${ }^{6}$ Revising different examples including the Peripatetics, Friedrich Nietzsche, Paul Klee, and Thomas Bernhard, he demonstrates that body and mind are inextricably linked and in process of constant affective feedback. ${ }^{7}$ Giersch suggests to determine this interplay as synchronization where the measured steps share the rhythm of a measured thought. Two "spheres" intermingle in the process of walking, connected by two-way resonances. ${ }^{8}$ This synchronization can provide mindstates like concentration, distraction, and pleasure, ${ }^{9}$ as described in Walser's The Walk. The walking figure repeatedly mentions the necessity to walk and its pleasures, explaining how walking frees him from fear and mistrust. ${ }^{10}$ In this respect, the activities of walking, thinking, and writing appear as synchronized spheres within The Walk although the walking body is absent. Walser's The Walk and All This Can Happen share the dimensions of walking acts which have sedimented in the composition: both pieces unfold complex walking-relations posing questions about body and mind, ecology, subjectivity, sociality, and modernity.

\section{(Not) Being in the Midst: Walking-relations}

Robert Walser's The Walk narrates a daylong walk through a (probably Swiss) small town and its rural environment from the perspective of a lonely stroller. The Walk reports episodically and in the shape of an inner monologue all that happened, or all that could have happened, during this meandering through the day. ${ }^{11}$ As the reader accompanies the walking figure passing the events, the novel develops a unity of fictional walking and reading time. By this experimental literary strategy of soliloquy, The Walk unfolds a subjective, experienced time. The walking and thinking spheres are synchronized with each other and therefore with the reader. One seems to be in the 
walking person's head while reading, co-walking, or even in-between the acts of walking, writing, and reading. This enables to connect with or to embody the situation-and not to identify, as identifying is often based on a story and its moral dimensions. In its perspective or mode of representation The Walk refers to the reader's own sensation of moving-in-the-world. Walser unfolds a space opening up by the flow of speech-leaving an invisible, imaginary line of walking behind eventually (choreo-graphy). At first glance, The Walk seems to have an underlying rhythm of speech that echoes the activity of walking: an alternating, seesawing, and balancing movement. It can be traced to John Hefferman's unvarying and even way of reading of The Walk as part of the soundscape in All this Can Happen. Within this basic rhythm, the walk is structured by all kinds of events and encounters. The walking figure is submitting a letter and meeting a friend called Frau Aebi, a tax assessor, and a tailor. The "better vagabond" 12 makes random acquaintance with a professor, a bank clerk, a book seller, a girl singing, and many others he sees from the distance, walking, riding bikes or in cars, sitting, standing, playing, singing, working, and so on. Furthermore, animals, flowers, books, clothes, and other objects find appearance in his description and co-create-in the process of walking-- heterogenous and "wonderful image of the humble present" where everything is "equally loved, the narrating figure asserts in the first part of the novel. ${ }^{13}$ This phrase gives the impression that the walker experiences even banal events as beautiful and finds moments of peace, love, and freedom in walking through the day. This seems so refer to different reflections on walking but to one early modernist idea in particular: in the second half of the nineteenth century Charles Baudelaire wrote an essay called "The Painter of Modern Life" $(1863)^{14}$ where he developed a concept of modernity and introduced a new idea of beauty. This idea did not ground in concepts of antiquity and classicism, like harmony, the statuesque, or the sublime, but in the ephemerality of daily-life itself, its fashions and changings in taste which are transitory but equally loved. "By 'modernity," Baudelaire explains in a central passage of the essay, "I mean the ephemeral, the fugitive, the contingent, the half of art whose other half is the eternal and the immutable." 15 It is only one of many notions of modernity but it discloses a fundamental shift in thinking in 19th century: from static concepts of beauty, to contemporaneity, to processuality, and to new definitions of time. Walser's work in prose was written fifty years later, and it certainly has different aesthetic intentions. ${ }^{16}$ Yet, Walser's walking figure experiences an "equal love" of things as he estimates daily-life objects and practices. By Walser's literary strategy in writing down a walking act, a flow of passing-by is taking place-like a celebration of "all that can happen," displaying an eternal beauty within the fugitive. Furthermore, Baudelaire described a shift in perspective from classicism to modernity by discussing the milieu-drawings of Constantin Guys. ${ }^{17}$ Guys serves as an example for the shift from "distance" to "closeness" in artistic practice, from painting to sketch, from result to process, from the studio as place of production to the outside world. In Walser, it is not the artist searching for an ephemeral motif to draw. The leisure-walker feels the necessity to 
walk and to collect impressions to distract him from his work (of writing); the writer Walser obviously composed his text after many walks and probably invented the events. But the Baudelairian artist and Walser's walker share the artistic strategy and perspective of being in-the-midst-of-things, in a milieu, instead of being distanced. Walking always already starts in the "midst" or the "thick" of things; there is no starting or entering point, only a transformation of relations between the self, others, and things - a process. ${ }^{18}$ Choreographically speaking, the walker is not overlooking the space from a vantage point, he is walking right in the midst, creating a shifting network. It is not walking in a Euclidian space Walser describes, but a productive navigation in the sense of Brian Massumi which co-generates space by passing. ${ }^{19}$ This produces an ecology of things, relations with all kinds of things. Yet, the way in which Walser describes the walking-relations, the protagonist loses his dominant position in the midst and in the world. He is not the center of the network; there is no control over things. Although the stroller is protagonist of the story, his subjectivity itself only exists in relation; it derives from the interaction with its environment. He is not autonomous; he is one of many elements within this network-tableau of nature and culture. This even corresponds to recent discourse on New Materialism and on the Agency of Things (Actor-Network-Theory), ${ }^{20}$ where concepts of nature are not grounded in questions of beauty or the fugitive anymore but in ideas of ecology and posthumanism and -anthropocentrism. For example, Bruno Latour and Jane Bennett have pointed out-also against the background of our ecological crisis-that smallest agents, animals, plants, dust particles, molecules, hormones, and vitamins cross our organisms and co-determine any situation. ${ }^{21}$ Uncountable factors produce a constellation. According to Latour and Bennett, contemporary art works can sensitize us for questioning hierarchical positions of the subject in ecological systems. ${ }^{22}$ In this respect, Walser's The Walk can be read as a reflection on ecology avant la lettre-but in a modernist way. The subject of his walk remains a walking figure that does not fully dissolve into its environment like it probably would in many contemporary art works. But throughout the reading process it becomes unseizable, loses its shape and becomes decentralized, fragmented by the way in which Walser composes different styles, languages, and events. In older traditions of walking, the person who is experiencing the world on foot is not questioned-for example, in Jean-Jacques Rousseau's Les Réveries du Promeneur Solitaire (1776/78) or in the idea of the flâneur as described by Walter Benjamin or Baudelaire. Here, discourses on bourgeois subjectivity as wholeness, on landscape and contemplation have been discussed. ${ }^{23}$ I cannot fully explore those concepts of subjectivity here. But in Walser's The Walk, it is neither the contemplative walker nor the urban stroller wandering the arcades, making "studies" and "actively inscribing the city." ${ }^{24}$ Walser's stroller seems to be inbetween many traditions in many respects. And this clearly refers to a modernist topic: being in-between nature and culture (small town, rural environment) mirrors a specific binarism of nature and culture. The casual events in The Walk are marked by this binarism of nature and culture, where the walking activity in nature is positively 
connoted against the background of (a certain type of) civilization. It generates joy and freedom; whereas industrial cars, work facilities, and recurrent military motives and metaphors invoke danger and terror to the walker. They associate violent civilization, rationalism, and the trauma of the First World War. ${ }^{25}$ This impression is not clearly articulated within The Walk but seems to be a subliminal content suggested by almost inconspicuous events. For example, when the walker worries that children playing on the street could be hit by cars, the fear is expressed rhythmically: children are playing freely and are menaced to be hurt or killed by cars shooting in. Two movements and rhythms clash in this metaphor: the (un-)coordinated rhythm of a playful group with many directions versus the speed and power of a machine, a linear and aggressive movement. Basically, riding in cars and trains can destroy the connection with nature, The Walk suggests. It recalls what Wolfgang Schivelbusch's argues in his Geschichte der Eisenbahnreise (the history of train travelling): that it transforms the relational body-experience into an accelerated and bodiless visual perception of the world-into a being separated from it. ${ }^{26}$ On the other hand, elements like cars and machines refer to an ideology of technical rationalism that points to the cruelest dimension of war.

It is by these struggling metaphors of nature and culture/civilization that Walser creates a tension of being in-between, a modernist angst to get lost in a complex and hostile world. Yet, the binarism of nature and culture is never strict in The Walk. Both seem inseparable and gradually cultivated; for example, the civilized pathways or flowery hats of ladies ${ }^{27}$ speak of this mutual reaction and interdependency between nature and culture. By the way which Walser's walker speaks about nature, there even seems a reflexive distance inscribed from time to time. The enthusiastic motto of a "humble present" seems so exaggerated that it appears more like a self-convincing mechanism than as "spontaneous" enunciation. The experimental composition of the whole novel suggests it could be a referential element to walking traditions like those by Rousseau and others, although we know that Walser himself highly appreciated walking as a practice of relaxation. The reader cannot figure out who is speaking here due to the literary strategy. Furthermore, nature and culture merge by a rhythmic composition and produce a constant transformation into each other: walking through the forest, the protagonist is calmly thinking and walking, whereas he is in haste when irritated by signs of civilization, war, and social power. This produces an overhang or imbalance within the literary walking act. Sensations of walking at an abyss or of losing the orientation are recurrently described within the text and emphasize this impression of bodily instability. And what is emphasized clearly is a bare necessity to continue walking, to move forward-to run from all social, economic, and political regimentation. 


\section{Getting lost: Movement and Rhythm in All This Can Happen}

In their filmic version of the walk, All This Can Happen, Siobhan Davies and David Hinton transport the reading experiences of shifting walking-relations onto the screen by using imagery, offscreen text, and sound. It is composed with found footage material from early film, colored or black and white, in different perspectivesarranged in different distances (cadrages). ${ }^{28}$ By the use of split-screens, time-lapses, freeze frames, repetitions, and other effects, they create a montage of different rhythms, intervals, and demonstrations of relationality-reinforcing the collage character given already in Walser.

Like in Walser's The Walk, various events and a variety of protagonists in countless daily-life activities and movements are presented. The human-beings depicted are opening windows, walking, jumping, working, marching, riding bikes or cars, swimming, climbing scaffolds, cleaning, laughing, milking cows, shouldering guns, dancing; either not noticing their being watched, or sitting and watching or posing for the camera. And non-human elements also co-create the scenery. Pictures of animals, plants, things, clothes, fog, an eclipse, and even undefinable microcosmic smallest materials (in time-lapse condensation) were collected and combined. In their equal appearance, these worldly things suggest there is no hierarchy between human, animal, thing, and smallest element. It appears like the anthropocentrism is being questioned, just like in, or even moreso than in, Walser's The Walk. All elements play the role of actants or actors (in the sense of Latour) and co-determine the situation and combining their own movements with the movements of others. ${ }^{29}$

Walser formed an in-between-ness of the walking figure by playing out the materiality of text and superimposing walking, writing, and reading processes. He conducted different types of texts and rhythm. But the text itself keeps a constant flow. It has rhythmic and thematic ruptures, but they are all re-arranged into a heterogeneous homogeneity of one text narrated by one figure: the perspective remains. In All This Can Happen, Davies and Hinton use the media specificity of film to split these ruptures even more: they fragment and multiply perspectives and walking acts. Voice and image are in tension as well as the imagery itself. There is no solid human figure to give order to the seen but the viewer. The narrator is just one equal auditory element amongst the other elements. Everything is floating or flowing, also due to the technical apparatus of film. Anything can happen, encounter each other, and (relappear in front of the viewer. This is how an anthropocentric position is challenged even more. There is no hierarchy between image and text, image and image, image and sound, motif and motif.

The walking events are not depicted mimetically like in a fictional film about a leisure walk. It seems to be a composition of time-images, in the sense of Gilles Deleuze, which create the scenery and reanimate the walk. ${ }^{30}$ In his cinema book, Deleuze 
differentiates movement-image from time-image. The movement-images of the narrative film build up a form of synthesis of images by montage, where time is represented in the film by an almost linear movement of things. Deleuze determines this process as the "sensomotoric scheme" or pattern to create illusion of a coherent world. ${ }^{31}$ The mise en scène of time-images like these in experimental films, on the other hand, separates time and movement; they are co-related differently. Optical and acoustic situations are composed autonomously and create complex relations between past, present, and future. This is what he defines as virtual, a catenation of elements and their time dimensions.

Based on this multitemporal complexity, All This Can Happen rebuilds and rearranges the metaphorical universe from Walser's The Walk. Material from the beginning of the 20th century invoke the atmosphere of a modern era which was marked by a social and cultural transformation, by economic growth and technical progress, by a relation between work and leisure time, and also by war, violence, and anxieties. By the use of documentary material All This Can Happen illustrates a subliminal texture of Walser's The Walk. It discloses the (non-)binarism of nature and modern civilization, of old- and new-world. All This Can Happen lays open the ambiguities which are suggested by Walser's depiction of walking joy and social forces. In Walser, the love of nature and leisure-walking is contrasted by all kinds of social and technical regulations. Yet, he shows the interdependencies of both. The Walk represents a fragile equilibrium of freedom and given structures. All This Can Happen produces, by the way the walker speaks, an overhang in the process of reading and generates the impression of haste and flight. The walker often is in a hurry and changes his tone dependent upon where he is-e.g. when in a hurry, the text is narrated through short, simple, and direct sentences so there is a change in speed in the language itself. And calm and poetic sequences, complex and compound, are given in the passage in the forest, for example. Furthermore there, is an abundance of quickly narrated information when he is talking about workers, town-views, and so on. In All This Can Happen, the images are arranged in different speeds as well and reproduce this rhythm by the use of contrasts: Images of nature and walking are being contrasted by images of military practices, like marching, shouldering guns, or working in ironworks. Furthermore, the splits and cuts accelerate the speeds and density whereas held frames and sometimes repetitions reduce the speed (for a little while). There is a basic rhythm to this: the impression of an even walking forward, or flow, is produced by the mechanical movement of the apparatus, like an imaginary tact (also suggested by the soundscore of read-aloud text of The Walk by John Hefferman). This fundamental time of the medium is combined with more fictional and compositional time-orders like arranging story sets where the imagery belongs together and illustrates the texts, such as the visit at Frau Aebi's or to a bookstore. These rhythmic dimensions are in tension like in all composed films. But in All This Can Happen, it is by the composition of speeds and fragments as well as the soundscape that produce a kind of accumulation or overhang of elements. The frames 
change very quickly, and their mechanical continuity gives the impression to the viewer of being out of control or overwhelmed, of being menaced by the deepness and violence of this maelstrom of images. There is sensation of vertigo and of getting lost between the images. By the interplay of sounds and images, the individual seems to be erased; this is also a metaphor for modern angst. Rhythm can be understood as a regular repetition of the irregular, a flow including deviations being associated with human activity, whereas tact is more regular. It points to a regularity of mechanical instruments -and therefore to civilization and modernity. ${ }^{32}$ The interplay of regularity and irregularity in tone in All This Can Happen creates layers of movement, intervals and tensions between the rhythms, and destabilizes the viewer.

The soundscape of All This Can Happen by Chu-Li Cheng is an important factor of this destabilizing effect. It consists of a mixing of natural and "artificial" sounds. There is a mechanical repetition of sound morphemes like bubbling of water, sizzling of fire, creaking of wood, and white noises and of pseudo-diegetic or belated sounds (like the ringing of bells, or tweeting of birds when a window is opened). This pseudo-diegesis or syncope creates tensions and voids again and enriches the complexity. An uncanniness lies in the relations between the different layers of sound and between images and sounds, as they all seem separate and yet combined, familiar and unfamiliar at the same time. Any causality, logic, or reliable coordinates to perceive the world are suspended. Furthermore, the quality of the sounds often tends to noise, to heavy and dark industrial sounds, an unfamiliar and menacing droning and humming-reminiscent of danger, war, and violence, speaking to the viewer affectively and immediately.

The audiovisual arrangement is not an illustration of text. It exceeds the given text constantly and opens up associations beyond-creating a sphere of non-explainable and felt dimensions. Especially, the walking act as fragile bodily movement is a leitmotif in All This Can Happen, and it is represented in many ways. Activities and modes of locomotion are recurring within the images. Traumatized soldiers try to find their balance in walking, precariously wobbling. A baby attempts to move forward by slipping along the ground in a funny way. Children are running, men and women hurrying to work. The walking activity is fragmented into different frames and pluralized, creating a reflexive response to Walser's piece, giving an almost tactile impression of the walker's instability and liminality.

Because of this, the aesthetic perception by the viewers is marked not only by an aesthetic pleasure in perceiving the composition, but the act of viewing the film brings great awareness to its form (rhythm and composition) and affective impact. It poetically activates sensations of relatedness and dependency. For example, when the reader tells about Tomzack, the giant, a moving image of a very tall male person in historic clothing and a hat is displayed. The image is arranged in split, together with red-glowing images from a fire in the woods, with a white owl that corresponds to the 
tall person in body-proportion. And it is combined with a close frame showing big hands and many smaller ones, then with a frame where a crowd and faces look up to the camera, and then with an apple crashing in a closing hand. In this composition of multiplication and repetition the impression of felt relations is given, transporting associated sensations and feelings, like being smaller, being weaker, being irritated, being eager to understand, and so on. Many small details create an affective field around the topos of a giant; he is not introduced verbally alone, or in comparison to another figure like in a fictional movie. Many relations are being shown and open up space for interpretation. Loneliness, otherness, and strength as affective qualities are suggested by the imagery and composition at the same time.

To conclude, the rhythmic compositions of movement in The Walk and All This Can Happen share choreographic dimensions of walking, like flow and irregularity, balance and imbalance, moments of potential falling, disorientation, and also social and cultural dimensions of walking as practice. They provide an aesthetic perception for the viewers that can be characterized as an affective participation and as an experience of instability and liminality.

\section{Biography}

Maren Butte, PhD is a theatre and dance scholar at the Research Institute for MusicTheatre Studies (fimt) at the University of Bayreuth. From 2011-2014 she was a research scholar at the Collaborative Research Centre "Aesthetic Experience and the Dissolution of Artistic Limits" at Free University Berlin, and from 2005-2009 at the Research Project "Iconic Criticism" (eikones) at the University of Basel. Her research fields are in dance and choreography (in relation to music and sound); affective processes and aesthetic experience; and intersections between theatre, dance, and film. A recent publication: Gabriele Brandstetter, Maren Butte, and Kirsten Maar (Hg.), Topographies of the Ephemeral, Bielefeld 2016 (upcoming).

Email: marenbutte@web.de

\section{Notes}

' Davies, Siobhan and David Hinton. All This Can Happen, Film, UK 2012, 50'.

${ }^{2}$ For definitions of choreography, compare recently Brandstetter, "Choreographie." 
${ }^{3}$ Giersch. "Der gemessene Schritt als Sinn des Körpers," 264.

${ }^{4}$ Ibid., 272. Levitation is my translation from the German term schweben here.

${ }^{5}$ In neuroscience and dance studies, the terms kinesthesia and proprioception are being used to characterize the dynamic interplay between bodily sensations or stimuli, gravity, weight, environment/ground, etc. See O'Shaughnessy, "Proprioception and the Body Image," esp. 177; Brandstetter, Egert and Zubarik (Ed.). Touching and to be touched.

${ }^{6}$ Giersch, "Der gemessene Schritt als Sinn des Körpers," 264.

${ }^{7}$ In the 20th and 21st centuries, with a shift from product to process in the first and second Avantgarde (Dada, Situationists, Surrealists, Fluxus, Happening, Environmental Art, etc.) different artists and choreographers like Richard Long, Hamish Fulton, On Kawara, Bruce Nauman, and others used walking as creative practice to explore the relations between body, mind, and space. See Brandstetter, Gabriele. "Schrittmuster: Über Gänge und Gangarten im Tanz," 72; Lucas, Raymond, "Taking a Line for a Walk"169, 172.

${ }^{8}$ Giersch, "Der gemessene Schritt als Sinn des Körpers", 266.

${ }^{9}$ Ibid., 267.

${ }^{10}$ Walser, Der Spaziergang, 20, 24, 49, 50.

${ }^{11}$ Ibid., 56.

${ }^{12}$ Ibid., 27.

13 lbid.

${ }^{14}$ Baudelaire, Charles. The Painter of Modern Life, 1-37.

${ }^{15}$ Ibid., 13.

${ }^{16}$ Research on Walser's œuvre has emphasized the experimental way of writing in The Walk, the playfulness in arranging times and styles and the reflexiveness to the process of writing and it materiality itself. But the categorization of Walser's work as modernist along with (depending on the definition of modernity) Mallarmé, Valèry or Hauptmann, Kafka, Döblin, Proust, Joyce, and others is difficult and cannot be fully explored here. Compare, for example, Evans, Robert Walsers Moderne, 9-15.

${ }^{17}$ Baudelaire, Charles. The Painter of Modern Life, 8.

${ }^{18}$ Ingold, Ways of Walking, 1-19.

${ }^{19}$ Massumi, "Strange Horizon. Buildings, Biograms and the Body Topologic," 178.

${ }^{20}$ Bennett, Vibrant Matter, 368-381.

${ }^{21}$ Ibid.

${ }^{22}$ For example, works by Pierre Huyghe (Untilled, 2013) or Donna Haraway that were presented at Documenta 13 showed explicit interest in animals and plants. And also the film Leviathan (2012) by Lucien Castaing-Taylor and Verena Paravel from 2012 engaged their viewers in a different perspective: the camera did not focus on human activity alone, it contingently followed movements of animals, of water, clouds, machines, boats, and human body parts.

${ }^{23}$ Albes, Der Spaziergang als Erzählmodell. Studien zu Jean-Jacques Rousseau, Adalbert Stifter, Robert Walser und Thomas Bernhard. 9, 10. 
${ }^{24}$ Benjamin, The Arcades Project, 454, as quoted by Lucas, "Taking a Line for a Walk," 170. The Situationsists will continue this tradition in the 20th century.

${ }^{25}$ Walser, Der Spaziergang, 20, 55.

${ }^{26}$ Schivelbusch, Die Geschichte der Eisenbahnreise, 269.

${ }^{27}$ Walser, Der Spaziergang, 26.

${ }^{28}$ The found footage material was discovered through research in several archives (BFI National Archive, British Pathé, Wellcome Library London, Étienne-Jules Marey, Collège de France Archive, et al.) by Lucie Sheppard, Piera Buckland, and Zoë Dickin.

${ }^{29}$ Latour, Reassembling the Social, 63-86.

${ }^{30}$ Deleuze, Das Zeit-Bild, 53-61.

${ }^{31}$ Ibid.

${ }^{32}$ Brüstle, Ghattan and Risi (Ed.). Aus dem Takt.

\section{References}

All This Can Happen. Dir. Siobhan Davies and David Hinton. UK, 2012. Film.

Albes, Claudia. Der Spaziergang als Erzählmodell. Studien zu Jean-Jacques Rousseau, Adalbert Stifter, Robert Walser, und Thomas Bernhard. Tübingen: Francke, 1999.

Baudelaire, Charles. "The Painter of Modern Life." The Painter of Modern Life and other Essays, ed. J. Mayne, London: Phaidon Press, 1995. 1-37.

Benjamin, Walter. "Robert Walser." Illuminationen. Ausgewählte Schriften 1. Suhrkamp: Verlag, 1997. 349-352.

- The Arcades Project. Trans. Ed. H. Eiland and Kevin McGlaughlin. Cambridge, MA:

Belknap of Harvard University Press, 1999.

Bennett, Jane. Vibrant Matter. A Political Ecology of Things. Durham: Duke University Press, 2010.

Bergson, Henri. Denken und Schöpferisches Werden: Aufsätze und Vorträge. Hamburg: Europ. Verlagsgesellschaft, 1993.

Brandstetter, Gabriele. Tanzlektüren: Körperbilder und Raumfiguren der Avantgarde. Frankfurt a.M.: Fischer, 1995.

. "Schrittmuster: Über Gänge und Gangarten im Tanz." Gehen. ed. S. Basel. Göttingen: Steidl, 2008. 66-75. 
. "Choreographie." Kunstbegriffe der Gegenwart von Allegorie bis Zip; Kunstwissenschaftliche Bibliothek Band 50. Für Gregor Stemmrich. Ed. J. Schafaff, Nina Schallenberg, and Tobias Vogt. Cologne: Walther König, 2013. 33-38.

Brandstetter, Gabriele, Gerko Egert, and Sabine Zubarik (Ed.). Touching and to be Touched: Kinesthesia and Empathy in Dance. Berlin/Boston: De Gruyter, 2013. https://doi.org/10.1515/9783110292046

Brüstle, Christa, Nadia Ghattan, and Clemens Risi (Eds.). Aus dem Takt: Rhythmus in Kunst, Kultur, Natur. Bielefeld: Transcript, 2005.

De Certeau, Michel. Kunst des Handelns [1980]. Berlin: Merve, 1988.

Deleuze, Gilles. Das Zeit-Bild: Kino 2. Frankfurt: Suhrkamp, 1991.

Evans, Tamara. Robert Walser's Moderne, Bern/Stuttgart: Francke, 1989.

Foster, Susan. "Walking and Other Choreographic Tactics. Danced Interventions of Theatricality and Performativity." Substance XXXI Special Issue on Theatricality. (2002): 25-146.

Giersch, Ulrich. "Der Gemessene Schritt als Sinn des Körpers: Gehkünste und Kunstgänge." Das Schwinden der Sinne. Ed. D. Kamper and Christoph Wulf. Frankfurt a.M.: Suhrkamp, 1984. 261- 275.

Ingold, Tim. Ways of Walking: Ethnography and Practice on Foot. Farnham: Ashgate, 2008.

Latour, Bruno. "On Actor-Network-Theory: A Few Clarifications." Soziale Welt, 47: 4 (1996): 368-381.

. Reassembling the Social: An Introduction to Actor-Network-Theory. Oxford: Oxford University Press, 2007.

Lucas, Raymond. "Taking a Line for a Walk." Ways of Walking: Ethnography and Practice on Foot. Farnham: Ashgate. 2008. 169-184.

Massumi, Brian. "Strange Horizon: Buildings, Biograms, and the Body Topologic." Parables for the Virtual: Movement, Affect, Sensation. Durham: Duke University Press, 2008. 177-220.

Middleton, Christopher. "A Parenthesis on the Discussion of Robert Walser's Schizophrenia." Robert Walser Rediscovered: Stories, Fairy-Tale Plays, and Critical Responses. Ed. M. Harman, Hannover, NH: University of New England Press, 1985. 190194. 
O'Shaughnessy, Brian. "Proprioception and the Body Image." The Body and the Self. ed. J. Bermudez Luis, Anthony J. Marcel, and Naomi M. Eilan. Cambridge: MIT, 1995. 175204.

Schaub, Mirjam. Gilles Deleuze im Kino: Das Sichtbare und das Sagbare. München: Fink, 2003.

Schivelbusch, Wolfgang. Die Geschichte der Eisenbahnreise: Zur Industrialisierung von Raum und Zeit im 19. Jahrhundert. Frankfurt a.M.. Fischer, 2000.

Walser, Robert. Der Spaziergang. Frankfurt a. M.: Suhrkamp, 1985. 